\title{
Early Pregnancy Failure: Medical versus Surgical Management
}

\author{
Begum $\mathrm{N}^{1}$, Akhter $\mathrm{S}^{2}$, Laila $\mathrm{L}^{3}$ \\ DOI:https://doi.org/10.3329/jafmc.v16i2.55302
}

\begin{abstract}
Introduction: Misoprostol is increasingly used to treat women who have a failed pregnancy may be due to blighted ovum (anembryonic gestation), incomplete abortion, missed abortion, inevitable abortion in the first trimester. Medical treatment with Misoprostol is an alternative to conventional surgical treatment. Use of Misoprostol is simple, highly acceptable, noninvasive and preferred by women. In addition to surgical risk and patient's preference, medical evacuation reduces the need for hospital stay and the overall management cost.
\end{abstract}

Objective: To determine the efficacy and safety of Misoprostol for evacuation of uterus in early pregnancy loss and to compare the result with surgical evacuation.

Materials and Methods: It was a prospective randomized study conducted on 50 patients at the department of Obstetrics and Gynaecology, Border Guard Hospital, Dhaka during the period from February 2018 to July 2019. Here 25 patients received Misoprostol as medical treatment and 25 patients received surgical treatment.

Results: Of the 25 women assigned to receive Misoprostol, $19(76 \%)$ had complete expulsion by 24 hours and $22(88 \%)$ by 7 days. Complete evacuation after 1 st dose was $68 \%$ and after 2 nd dose $88 \%$. Misoprostol treatment failed in $3(12 \%)$ cases and required surgical evacuation. Among the respondents $80 \%$ women stated that they would use Misoprostol again if the need arises.

Conclusion: Medical treatment with Misoprostol is a cheaper alternative to surgery. Given its success rate near about $88 \%$ with mild side effects controllable with additional medication and above all patient's satisfaction, it should be prioritized over the evacuation curettage in patients who meet the treatment criteria.

Key-words: Early pregnancy failure, Medical treatment, Misoprostol, Surgical treatment.

\section{Introduction}

Early pregnancy failure means loss of pregnancy by any means (blighted ovum, incomplete abortion, missed abortion, inevitable abortion or etc.) in first trimester (before 12 weeks of pregnancy). It is one of the most common gynaecological problems in this day to day practice. Clinical spontaneous pregnancy loss complicates $8 \%$ to $20 \%$ of pregnancies, of which $80 \%$ occur before 12 weeks of gestation ${ }^{1}$. Approximately one out of four women will have an early pregnancy loss during her life time $e^{2}$. The use of sensitive pregnancy test and the accessibility of ultrasound have led to an increase number of diagnosed miscarriages ${ }^{3}$.

Traditionally, the gold standard method for the management of early pregnancy loss has been uterine evacuation by aspiration curettage. However, several studies have proposed medical treatment with Misoprostol as an alternative to conventional surgical treatment ${ }^{4,5}$. Surgical evacuation under anesthesia has certain morbidity, such as the risk of anesthesia, uterine perforation, intrauterine adhesions, cervical trauma and infections leading to infertility, pelvic pain and increased chance of ectopic pregnancy, ${ }^{6,7}$. In 2005, Zhang et al ${ }^{8}$ published a randomized clinical trial demonstrating Misoprostol to be an acceptable alternative to surgical treatment for the management of early pregnancy loss in terms of effectiveness, safety, acceptability and adverse effects. Recent evidences show that using Misoprostol as an alternative to surgery is simple, highly acceptable noninvasive method reduces the cost of services and may be preferred by women'. So the medical treatment with Misoprostol now regarded as being the primary option for the management of early gestational loss in most of the hospitals. Surgical evacuation, however, remains the management of choice in cases of heavy and uncontrolled bleeding or if there is evidence of septic abortion.

The medical treatment of first-trimester spontaneous abortion has several advantages over surgical treatment: it can be provided in an outpatient regimen; it does not require hospital admission or anesthesia; and it seems to more cost-effective treatment than surgical treatment ${ }^{9-11}$. Chemically Misoprostol is a synthetic prostaglandin analogue. It is extensively absorbed, de-esterified to Misoprostol acid, then to prostaglandin $\mathrm{F}$ analogue. Its half-life is $20-40$ minutes and excreted $80 \%$ through renal system and $15 \%$ by fecal route ${ }^{12}$. It can be administered by oral, vaginal, sublingual and per rectal route ${ }^{10}$. Studies showed that vaginal application of Misoprostol increases the success rate and reduces the side effects. It is a drug that is Food and Drug Administration (FDA) approved in United States for the prevention of Non-steroidel Anti-inflammatory Drugs (NSAID) induced gastric ulcers $^{13}$. The lowest effective dose of Misoprostol for each condition for which it is used is not yet clear and the dose differs in different categories of pregnancy loss ${ }^{14}$.

1. Lt Col Nasima Begum, MBBS, DGO, FCPS, Classified Specialist in Obs \& Gynae, Border Guard Hospital, Dhaka (E-mail: nasima100999@gmail.com) 2. Lt Col Shahnaz Akhter, MBBS, DGO, FCPS, Classified Specialist in Obs \& Gynae,Associate Professor, AFMC, Dhaka 3. Lt Col Luna Laila, MBBS,MCPS, DGO, Graded Specialist in Obs \& Gyne, Border Guard Hospital, Dhaka. 
Misoprostol is cheap, stable at room temperature, easy to transport, does not require refrigeration and readily available in most part of the country. It interacts with prostaglandin receptors, causes the cervix to soften and uterus to contract resulting in the expulsion of the uterine content ${ }^{15}$. There are some side effects of Misoprostol, such as abdominal cramping and per vaginal bleeding etc. which vary significantly in both duration and severity. Other side effects are fever, nausea, vomiting, diarrhea, dizziness, headache, chills, and pelvic pain. Giving growing emphasis on improving female health, it is undoubtedly becoming more important at present and in the future to treat a case of early pregnancy loss by a safe method. If Misoprostol is found to be safe and effective, a large number of patients will be benefitted and will escape from surgical intervention and complications. So, the aim of this study is to evaluate the efficacy, safety and acceptability of the treatment and also to compare its effectiveness with surgical evacuation as management of early pregnancy loss as well as to reduce the frequency of surgical evacuation procedures and the risks associated with them.

\section{Materials and Methods}

It was a prospective randomized study conducted on 50 patients at the department of obstetrics and gynaecology, Border Guard Hospital, Dhaka during the period from February 2018 to July 2019. Randomization was done by the desire of the patients after explaining them about the two methods of evacuation. Inclusion criteria were missed abortion $<12$ weeks gestation, incomplete abortion $<12$ weeks gestation with minimum pervaginal bleeding and blighted ovum. Patients having incomplete abortion of $>12$ weeks gestation, incomplete abortion with excessive pervaginal bleeding, history of medical disorders like cardiac, respiratory, renal, hepatic or adrenal diseases, anaemic patients $(\mathrm{Hb} \%<8$ gm\%), allergy to prostaglandin or NSAID, induced abortion etc. were excluded. After formulation of the study a data collection sheet was made which include all relevant parameters. A total of 50 women with first trimester pregnancy loss was randomly assigned to receive 800 microgram of tablet Misoprostol per vaginally or to undergo evacuation and curettage operation. Twenty-five patients received medical treatment and 25 patients received surgical treatment. Gestational age was determined from the 1stday of last menstruation according to menstrual history and trans-abdominal ultrasonography. A medical history was taken and a physical examination was performed by principal author. A base line blood sample was obtained for $\mathrm{Hb} \%$, blood sugar, blood for $\mathrm{ABO}$ grouping and Rh typing from selected patients.

Methods of medical evacuation: On admission in hospital patients who were selected for medical treatment were received 800 microgram Misoprostol vaginally by digital insertion into the posterior fornix. Interval between administration of Misoprostol and expulsion of product of conception was recorded. If expulsion of product of conception occurred after giving 1st dose then trans-abdominal ultrasonography was done to see the completeness of expulsion of product. If expulsion had not been occurred within 24 hours then 2 nd dose of Misoprostol was given in the same manner. After 7 days they were advised for trans-abdominal ultrasonography to see the completeness of expulsion of product. If sonography showed incomplete expulsion then surgical evacuation was done.

Methods of surgical evacuation: Similarly women who were selected for surgical treatment dilatation, evacuation and curettage were done. Every woman was advised for follow up on 15th day and was asked to complete the data collection sheet about duration and intensity of bleeding, intensity of pain and other side effects of the treatment e.g. fever, diarrhea, headache etc. and ultimately to the acceptability of treatment. Surgical treatment was considered failed where 2nd intervention was needed because of abnormal per vaginal bleeding and persistence of signs of retained product of conception. All relevant information for each of the study subject was recorded on pre designed data collection sheet. Obtained data were compiled on a master chart first then were organized by using scientific calculator and standard statistical formula. Percentages were calculated to find out the proportion of the findings. Further statistical analysis was done by SPSS. The results were presented in tables, figures, diagrams etc. For significance of difference Chi square test was done and ' $p$ ' value $<0.05$ was considered significant.

\section{Results}

Out of 25 women receiving medical treatment $32 \%$ were at or below 20 years of age, $32 \%$ were para- $1,60 \%$ gestational age between $9-12$ weeks. Out of 25 women receiving surgical treatment $28 \%$ were at or below 20 years of age, $36 \%$ were para-2,64\% gestational age between 9-12 weeks. Patient receiving medical treatment in early pregnancy loss included $48 \%$ incomplete abortion, $24 \%$ missed abortion, $8 \%$ inevitable abortion and 20\% anembryonic gestation. Patients getting surgical treatment included $40 \%$ missed abortion, $24 \%$ incomplete abortion, 20\% inevitable abortion and $16 \%$ anembryonic gestation (Table-I). Majority of respondents (52\%) in medical treatment were not needed any blood transfusion and $12.0 \%$ needed transfusion of 2 units of blood. In surgical treatment group $44 \%$ respondents needed transfusion of 2 units of blood. This difference between two groups was statistically highly significant $(p<0.05)$. Maximum respondents $(48 \%)$ of medical treatment group were discharged from hospital within 1-2 days. But $40.0 \%$ respondents of surgical treatment were needed hospital stay for $>3$ days. This difference between two groups was not statistically significant $(p>0.05)$. In medical treatment group $20 \%$ respondents developed per vaginal bleeding, $24 \%$ had lower abdominal pain and $8 \%$ had fever. But in surgical treatment group maximum $28 \%$ developed per vaginal bleeding, $8 \%$ had lower abdominal pain and $4 \%$ had fever. This difference between two groups was not statistically significant $(p>0.05)$ (Table-II).

In this study complete evacuation occurred in $17(68 \%)$ after 1 st dose of Misoprostol but $8(32 \%)$ patients remained incomplete. 
After administration of 2 nd dose, in 5(20\%) patients complete evacuation occurred and $3(12 \%)$ patients remained incomplete who required surgical evacuation. Study also found that medical treatment was accepted by $20(80 \%)$ of women but $15(60 \%)$ women accepted surgical treatment and this difference was not statistically significant $(p>0.05)$. In most cases $15(60 \%)$ expulsion was occurred by 12 hours of application of Misoprostol, 4(16\%) cases by $12-24$ hours, $3(12 \%)$ cases needed more than 24 hours and $3(12 \%)$ cases didn't response by Misoprostol and needed surgical evacuation (Table-III).

Table-I: Obstetric history of respondents $(n=50)$

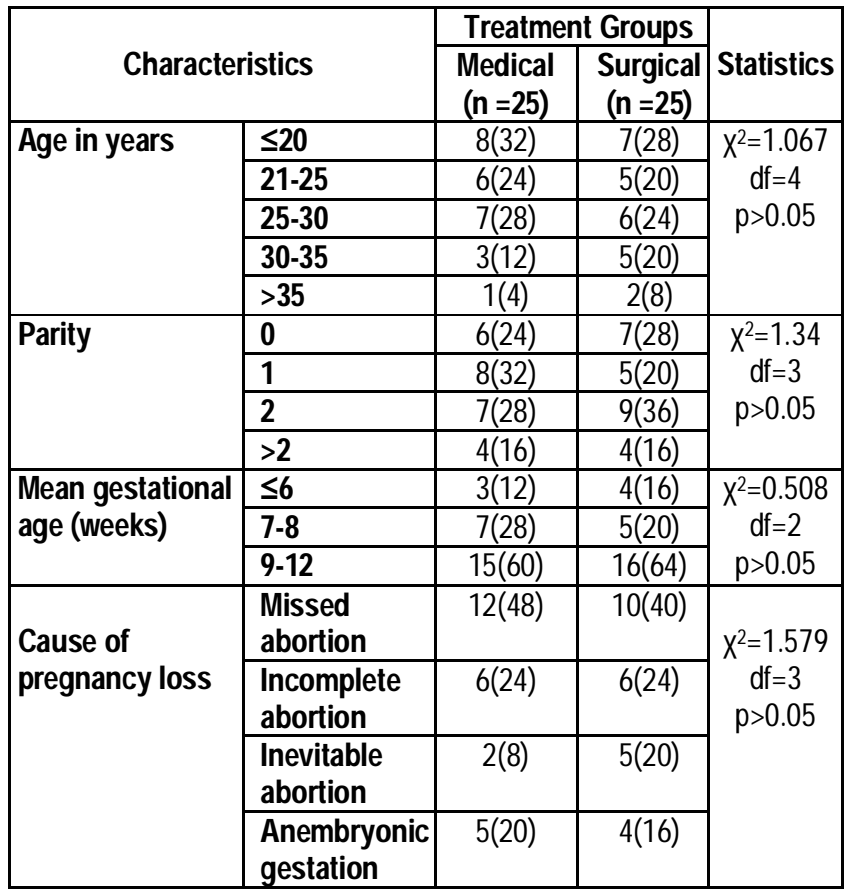

- Percentage in parenthesis

Table-II: Distribution of respondents by blood transfusion, hospital stay, complications and compliance $(n=50)$

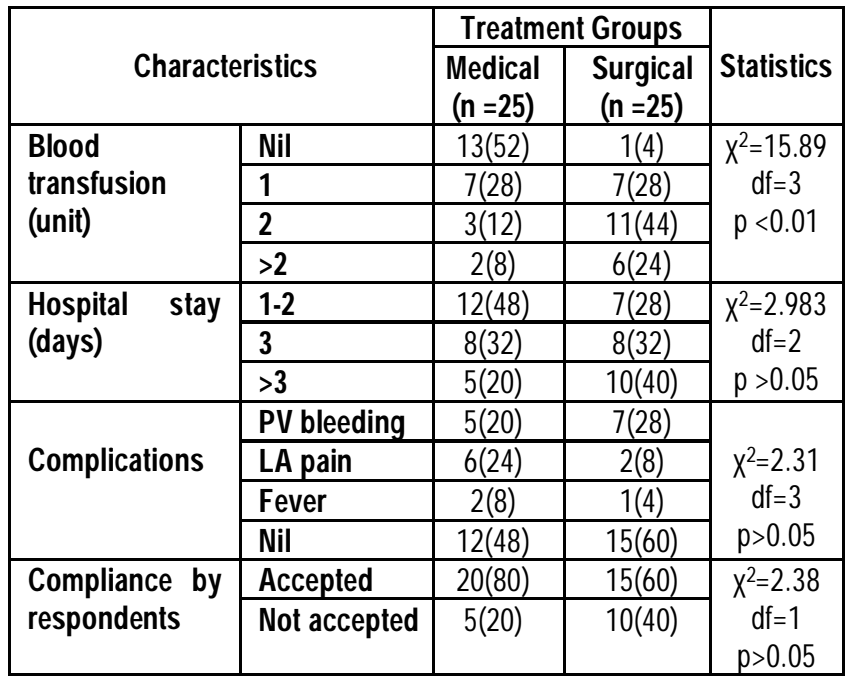

- Percentage in parenthesis * $P V=$ per vaginal, * $L A=$ lower abdominal
Table-III: Distribution of respondents by treatment response and time required after Misoprostol insertion ( $\mathrm{n}=25)$

\begin{tabular}{|c|c|c|c|}
\hline \multicolumn{2}{|c|}{ Characteristics } & Frequency & Percentage \\
\hline \multirow{5}{*}{$\begin{array}{l}\text { Treatment } \\
\text { response of } \\
\text { Misoprostol }\end{array}$} & $\begin{array}{l}\text { Complete evacuation } \\
\text { after } 1^{\text {st }} \text { dose }\end{array}$ & 17 & 68 \\
\hline & $\begin{array}{l}\text { Incomplete evacuation } \\
\text { after } 1^{\text {st }} \text { dose }\end{array}$ & 8 & 32 \\
\hline & $\begin{array}{l}\text { Complete evacuation } \\
\text { after } 2^{\text {nd }} \text { dose }\end{array}$ & 5 & 20 \\
\hline & $\begin{array}{l}\text { Incomplete evacuation } \\
\text { after } 2^{\text {nd }} \text { dose }\end{array}$ & 3 & 12 \\
\hline & Need surgical evacuation & 3 & 12 \\
\hline \multirow{6}{*}{$\begin{array}{l}\text { Time required } \\
\text { for expulsion } \\
\text { of product of } \\
\text { conception }\end{array}$} & $<6$ hours & 3 & 12 \\
\hline & 6-12 hours & 12 & 48 \\
\hline & 12-24 hours & 4 & 16 \\
\hline & $1-2$ days & 2 & 8 \\
\hline & 3-7 days & 1 & 4 \\
\hline & Not evacuated & 3 & 12 \\
\hline
\end{tabular}

\section{Discussion}

Medical management of early pregnancy loss is becoming increasingly popular. Our study indicates that treatment of early pregnancy loss with 800 microgram of Misoprostol vaginally, with the dose repeated after 24 hours when necessary is efficacious. The success rate by day 07 was $88 \%$. The risk of hemorrhage and pelvic infection were very low and the side effects were tolerable and minimum. Misoprostol treatment was acceptable to most of women. The efficacy of Misoprostol treatment for early pregnancy loss has varied greatly (ranging from $13 \%$ to $100 \%$ ) in previous retrospective and prospective studies ${ }^{16}$. This variation may be due to small sample size, the type of pregnancy loss, the dose of Misoprostol and the criteria used to define success.

The study of Herabutya and Presertwawat (1997) showed that 200 microgram vaginal Misoprostol caused a significant increase in the passage of tissue mass when compared with a placebo(17.1\% $)^{17}$. In our study we have used 800 microgram Misoprostol per vaginally. In about $48.0 \%$ of women expulsion of uterine content had occurred after 1st dose of Misoprostol and found empty uterine cavity within 6-12 hours and in 64\% of women complete expulsion occurred within 12-24 hours. In a study of Zhang et al(2005) showed treatment of early pregnancy loss by 800 microgram of Misoprostol vaginally with the dose repeated after 48 hours. The success rate by day 3 was $84 \% 8$.

Zalany $1^{18}$ treated 25 women with missed abortion at less than 13 week gestation using 200 microgram of intravaginal Misoprostol at every 4 hours for a total 4 dose. He reported $88 \%$ success rate after the 3rd dose and no further success after the 4th dose. Absence of echogenic structures more than $15 \mathrm{~mm}$ in anteroposterior diameter in trans vaginal ultrasound was used as a criterion for success. Creinin et al ${ }^{19}$ showed $88 \%$ success rate in treating early missed abortion with vaginal Misoprostol (800 microgram), in two doses 24 hours apart. They considered the absence of an intrauterine gestational sac as a criterion for complete evacuation. Rokeya Begum R et a ${ }^{20}$ showed $94 \%$ success 
rate in treating missed abortion at or below 14 weeks gestation with intravaginal Misoprostol, 400 microgram 6 hourly with maximum 3 doses. Complete expulsion and cervical dilatation with protrusion of product of conception at cervical os were used as the criteria for success. Here we have used 800 microgram of intravaginal Misoprostol in 1 or 2 doses 24 hours apart at or below 12 weeks and the success rate by day 15 was $88 \%$. Criterion used for success was as same as Begum $R$ et al ${ }^{20}$. The of the regimen of the present study is, it requires fewer vaginally applications of drug. It avoids considerable number of operations and when complete expulsion does not occur it usually provides adequate cervical dilatation making surgical evacuation easy and less completed; duration of hospital stay is also shortened. In this study, $48 \%$ of women receiving Misoprostol is discharged from hospital within 1-2 days and $32 \%$ within 3 days. 20\% require hospitalization for more than 3 days. High success rates as well as low side effects of this approach seems to lead to a high satisfaction rate with this treatment compared to surgical treatment. Medical treatment is accepted by $80 \%$ of the responder, in comparison surgical treatment by $60 \%$. In this study $20 \%$ of women getting Misoprostol developed per vaginal bleeding and requires transfusion for more than two units. Misoprostol treatment was acceptable to most women. It is a cheap substance and easy to store.

This allows a significant reduction in the cost of management by avoiding anesthetic and theater cost. We found that women with incomplete or inevitable spontaneous abortion were more likely to have complete expulsion after one dose of Misoprostol than those women with embryonic or foetal death or women with an anembryonic gestation. However by using a second dose a similarly high success rate is required. Although the success rate was higher (98\%) in surgical control group, patient satisfaction was significantly higher in groups using Misoprostol (80.0\%). Reasons for dissatisfaction in the surgical group were long waiting time for treatment and uncertainty of the time of operation. Our study did not reveal whether 800 microgram of Misoprostol represents the lowest effective dose for all subtypes of early pregnancy loss. Another observation in our study was that there were additional benefits of using Misoprostol treatment. The patients who needed surgical evacuation had soft and dilated cervix at the time of evacuation which reduces the risk of perforation and cervical injury. Research on finding of optimal dose in order to increase efficient evacuation for Misoprostol treatment is warranted. Our trial involved a 15 days follow up period. The vast majority of patients recovered satisfactorily within this period (88.0\%). But a small number required surgical evacuation even after 2 weeks.

\section{Conclusion}

This randomized control study demonstrated the efficacy and safety of the administration of 800 microgram of Misoprostol intravaginally for the management of missed, incomplete and anembryonic abortion. Larger studies are needed to conclude that whether the treatment can be considered as an outpatient basis.

\section{References}

1. Sifakis S, Angelakis E, Vardaki E et al. High-dose Misoprostol used in outpatient managementof first trimester spontaneous abortion. Arch Gynecol Obstet. 2005; 272:183-6.

2. Alberman E. Spontaneous abortion: Epidenology. In: Stabile 1; Grudzinskas G, Chard T eds. Spontaneous abortion: Diagnosis and treatment. London: Spriger-Verlag. 1992:19-20

3. Demetroulis C, Saridogan E, Kunde DAA et al. A prospection randomized trial comparing medical and surgical treatment for early pregnancy failure. Hum Reprod. 2001; 16(2):365-9.

4. Trinder J, Brocklehurst P, Porter R et al. Management of miscarriage: Expectant, medical, or surgical? Results of randomized controlled trial. BMJ. 2006; 332:1235-40.

5. Graziosi GCM, Mol BWJ, Reuwer PJH et al. Misoprostol versus curettage in women with early pregnancy failure after initial expectant management: A randomized trial. Hum Repord. 2004; 19:1894-9.

6. Creinin MD. Randomized comparison of efficacy, acceptability and cost of medical versus surgical abortion. Contraception. 2000; 62:117-24.

7. Hertig At. Livingstone RG; Spontaneous, threatened and habitual abortion. Pathogenesis and treatment N Engl J Med. 1994; 230:797-806.

8. Zhang J, Gilles JM, Barnhat K et al. A comparison of medical management with Misoprostol and surgical management for early pregnancy failure. N Engl J Med. 2005; 353:761-9.

9. Bagrtee JS, Khullar V, Regan L et al. A randomized controlled trial comparing medical expectant management of first trimester miscarriage. Human reproduction. 2004; 19:266-271.

10. Xia W, She S, Lam T, Medical versus surgical abortion methods for pregnancy in china: A cost minimization analysis. Gynaecol Obstet Invest. 2011: 72:257-63.

11. You JHS, Chung TKH. Expectant, medical or surgical treatment for spontaneous abortion in first trimester of pregnancy: A cost analysis. Hum Repord. 2005; 20:2873-8.

12. Rausch $M$, Lorch $S$, Chung $K$ et al. A cost-effectiveness analysis of surgical versus medical management of early pregnancy loss. Fertil Steril. 2012; 97:355-60.

13. Pang MW, Lee TS, Chung TK. Incomplete miscarriage: A randomized controlled trail comparing oral with vaginal misoprostol for medical evacuation. Hum Reprod. 2001; 16(11):2283-87.

14. Bagratee JS, Khullar V, Regan $L$ et al. A randomized controlled trial comparing medical and expectant management of first trimester miscarriage. Human Reproduction. 2001:266-71.

15. Jhang J, Gllies JM, Barnhart $K$ et al. A comparison of medical 
management with Misoprostol and surgical management for early pregnancy failure. N Engl J Med. 2005; 353:761-9.

16. Baird DT. Mode of action of medical methods of abortion. J Am Med Womens Assoc (1972). 2000; 55(3 Suppl):121-6.

17. Herabutya $Y$ and Prasertwawat PO. Misoprostol in the management of missed abortion. Int J Gynaecol Obstet. 1997; 56:263-6.
18. Zalanyi S. Vaginal misoprostol alone is effective in the treatment of missed abortion. BR J Obstet Gynacol. 1998; 105(9):1026-8.

19. Creinin MD, Moyer R, Guido R. Misoprostol for medical evacuation of early pregnancy failure. Obstet Gynacol. 1997; 89 (5 Pt 1):768-72.

20. Begum R, Baurua $S$, Nahar $S$. Misoprostol for missed abortion. Bangladesh. J Obstet Gynaecol. 2004; 19(2):61-5 